\title{
Lower extremity edema in patients with early ovarian cancer
}

\author{
Myong Cheol Lim ${ }^{1,2^{*}}$, Jeong Seon Lee ${ }^{1}$, Byung Ho Nam³ , Sang-Soo Seo ${ }^{1}$, Sokbom Kang ${ }^{1,2}$ and Sang-Yoon Park ${ }^{1,2^{*}}$
}

\begin{abstract}
Background: The objective of this study was to investigate clinical manifestations of lower extremity edema (LEE) in early ovarian cancer.

Methods: Patients with early ovarian cancer who underwent staging surgery between January 2001 and December 2010. Medical records for LEE and/or responses to the Gynecologic Cancer Lymphedema Questionnaire (GCLQ) were evaluated.

Results: Patients had a median age of 46 years. Twenty-nine patients (40.8\%) had past (13 patients, 44.8\%) and/or current patient-reported LEE (16 patients, 55.2\%). Symptoms reported on the GCLQ in over 20\% of respondents were numbness, firmness/tightness, swelling, heaviness, limited movement of knee, and aching. GCLQ total symptoms score was significantly higher in patients with current LEE. Most of the LEE (25/29, 86.2\%) developed within 12 months after surgery and LEE lasted more than 6 months in approximately two-thirds of the patients $(18 / 29,62.1 \%)$. Only half of the patients (52.1\%) indicated knowledge of lymphedema: $86.2 \%$ of LEE patients and $28.6 \%$ of patients with no LEE.
\end{abstract}

Conclusions: Although a significant proportion of patients with ovarian cancer have LEE after surgery, most are not aware of lymphedema until they develop. Education and analyses for LEE and lymphedema are needed in patients with ovarian cancer.

Keywords: Ovarian cancer, Lymphedema, Lower extremity edema

\section{Background}

Ovarian cancer is continuously increasing and the mortality is high [1-3]. Current standard treatment is cytoreductive surgery including lymph node dissection (LND) and chemotherapy. When there is no visible and palpable tumor in the peritoneal cavity during surgery, systematic pelvic and paraaortic LND is performed for staging and debulking. For advanced bulky ovarian cancer, the high rate of recurrence, which affects approximately two-thirds of the patients, is a critical issue. On the other hand, quality of life is one of the important concerns for patients with early stage ovarian cancer.

\footnotetext{
* Correspondence: gynlim@gmail.com; sypark.ncc@hotmail.com

${ }^{1}$ Center for Uterine Cancer, Research Institute and Hospital, National Cancer Center, 323, Ilsan-ro, Ilsandong-gu, Goyang-si 410-769, Gyeonggi-do, Republic of Korea

${ }^{2}$ Gynecologic Cancer Branch, Research Institute and Hospital, National Cancer Center, 323, Ilsan-ro, Ilsandong-gu, Goyang-si 10-769, Gyeonggi-do, Republic of Korea

Full list of author information is available at the end of the article
}

Lower extremity edema (LEE) after surgical treatment is one of the most important problems for women with ovarian cancer. About $20 \%$ of ovarian cancer patients develop LEE [4]. However, previous studies suffered from critical limitations in terms of reproducibility because of the heterogeneous study cohort that included patients with cervical, uterine, and vulvar cancer. Clinical information, such as stage, was not included [4-6]. Records concerning LEE and lower leg lymphedema (LLL) have been inconsistent. Generally, LEE is reported by patients as a questionnaire response and LLL is for the clinical diagnosis.

We investigated the clinical manifestations of LEE and LLL in patients with early ovarian cancer and reviewed the literature of LEE and LLL in patients with ovarian cancer. 


\section{Methods}

After obtaining Institutional Review Board (National Cancer Center, Korea) approval (NCCNCS-12-565), we reviewed medical records of patients with early ovarian cancer (FIGO stage I and II) at National Cancer Center who underwent cytoreductive and staging surgery between January 2001 and December 2010. Inclusion criteria were early stage epithelial ovarian cancer, no active treatment, available telephone communication with patients, and ability and willingness to provide verbal informed consent.

Medical records were reviewed. All patients who met the inclusion criteria were contacted by a telephone call by a investigator (JS LEE). The telephone interview questionnaire for LEE and gynecologic cancer lymphedema questionnaire (GCLQ) took approximately $20-30 \mathrm{~min}$ to complete. The questionnaire for LEE included onset, severity, location, duration, and management. Patients were also questioned concerning deep vein thrombosis to exclude other causes of LEE. LEE was defined as subjective edema of lower extremity based on patients' complaint. LLL was defined based on a clinical diagnosis of lymphedema by a physician.

A previously developed GCLQ was pilot tested with patients with gynecologic cancers [7]. The GCLQ is satisfactory to distinguish patients with and without LEE [area under the curve (AUC), 0.95] and is easy to use. The patient-self-reported symptom scores, GCLQ, included seven symptom clusters: heaviness (item 14), swelling (general; items 8, 9, 20), swelling (limb; items 18, 19), infection-related (items 10 [redness], 11 [blistering], 13 [increased temperature in leg), aching (item 17), numbness (items $7,12,15,16$ ), and physical functioning (items 1-6) [7]. In the current study, Korean version of GCLQ (GCLQ-K) which was developed after minimal modifications from original GCLQ by our research team and showed high internal consistency and reproducibility was used [8]. In addition, ever or current LEE, location and onset of LEE, and any symptoms related to LEE were evaluated. Past LEE was an experience of LEE during a certain period and no current LEE. Current LEE was the existence of LEE at the time of survey irrespective of the onset of LEE. Ever LEE included the entire past and current LEE.

\section{Results}

Of 96 patients with early epithelial ovarian cancer, 71 patients were contacted by telephone and their medical records were available (Figure 1). Characteristics of evaluable patients for LEE $(n=71)$ including age, body mass index, type of disease, FIGO stage, histology, CA125, and LN dissection are presented in Table 1. Most patients had ovarian cancer $(n=69)$ and the remaining two patients had tubal cancer. Fifty-two and

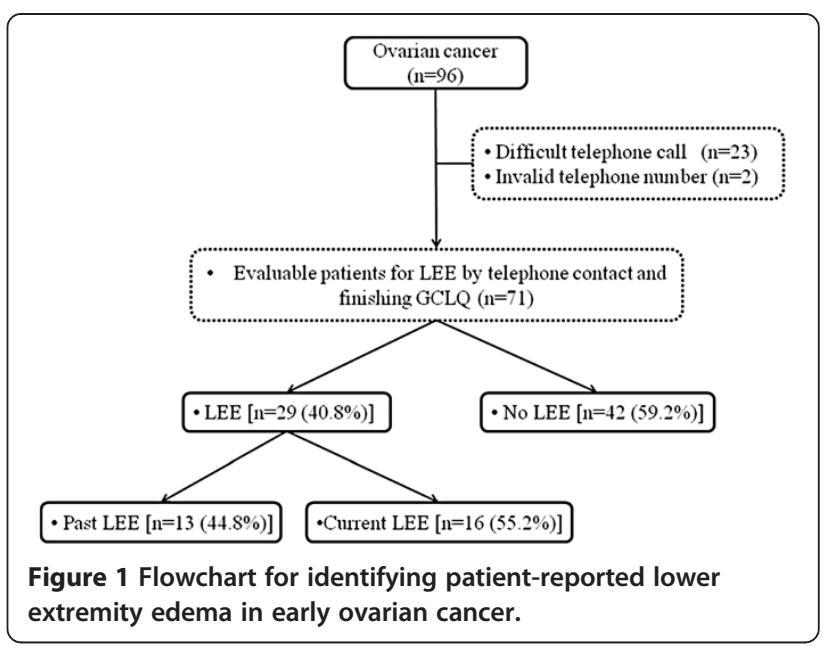

19 patients were identified and comprised the current FIGO stage I and II groups, respectively. The median age of the patients was 46 years (range, 22-65 years). Fifteen patients $(21.1 \%)$ had serous histology. The remaining 56 patients $(78.9 \%)$ had non-serous histology: mucinous $(\mathrm{n}=11,15.5 \%)$, endometrioid $(\mathrm{n}=14,19.7 \%)$, clear cell carcinoma $(n=15,21.1 \%)$, transitional cell ( $\mathrm{n}$ $=3,4.2 \%)$, and other including mixed carcinoma $(\mathrm{n}=13$, 18.3\%). Serum CA-125 was checked preoperatively in 68 patients (95.8\%); 39 patients (57.4\%) had elevated serum CA-125 level $(\geq 35 \mathrm{U} / \mathrm{mL})$. The median value of serum CA-125 was $42 \mathrm{U} / \mathrm{mL}$ (range, 1.9-4389 U/mL). Sixty-one patients $(85.9 \%)$ received chemotherapy, which consisted of paclitaxel and carboplatin in 39 patients, paclitaxel and cisplatin in 20 patients, and cyclophosphamide and cisplatin (+Adriamycin) in two patients.

Of 71 evaluable patients, $29(40.8 \%)$ patients had or previously had LEE. Of 29 patients, 16 patients (55.2\%) had current LEE and 13 patients (44.8\%) had past LEE. Clinical LLL was diagnosed in nine patients with ovarian cancer. All nine patients with a clinical diagnosis of LLL were included in the group of patients with LEE. One patient did not remember the exact onset time and endpoint of LEE. Onset time and end-point of LEE could not be precisely identified in one and five patients, respectively. Accordingly, the duration of LEE was not definitive in seven patients. Figure 2 depicts the onset and duration of LEE. In the 27 patients with a clear onset of LEE, LEE occurred within 1 month after LND in 17 (63\%), within 3 months after LND in five (18.5\%), within 6 months after LND in two (7.4\%), and within 12 months after LND in one (3.7\%). In two patients, LEE developed 51 and 72 months after LND. More than half of the patients $(16 / 29,55.2 \%)$ had LEE at time of completing the questionnaire. In the 22 patients with a clear duration of LEE, the duration of LEE was within 6 months in six 


\begin{tabular}{|c|c|}
\hline Characteristics & Total \\
\hline \multicolumn{2}{|c|}{ Age (year) at time of operation } \\
\hline Median (range) & $46(22-65)$ \\
\hline Body weight (kg) & $55.6(42-78)$ \\
\hline Height (cm) & $158(144-165)$ \\
\hline Body mass index & $23(15.6-34.6)$ \\
\hline \multicolumn{2}{|l|}{ Type of disease, n (\%) } \\
\hline Ovarian cancer & $69(97.2 \%)$ \\
\hline Tubal cancer & $2(2.8 \%)$ \\
\hline \multicolumn{2}{|l|}{ Stage (FIGO, 1989), n (\%) } \\
\hline la & $25(35.2 \%)$ \\
\hline $\mathrm{lb}$ & $1(1.4 \%)$ \\
\hline Ic & $26(36.6 \%)$ \\
\hline Ila & $1(1.4 \%)$ \\
\hline $11 \mathrm{~b}$ & $10(14.1 \%)$ \\
\hline Ilc & $8(11.3 \%)$ \\
\hline \multicolumn{2}{|l|}{ Histology, n (\%) } \\
\hline Serous & $15(21.1 \%)$ \\
\hline Mucinous & $11(15.5 \%)$ \\
\hline Endometrioid & $14(19.7 \%)$ \\
\hline Clear cell & $15(21.1 \%)$ \\
\hline Transitional cell & $3(4.2 \%)$ \\
\hline Others including mixed & $13(18.3 \%)$ \\
\hline \multicolumn{2}{|l|}{ CA125 (U/mL)* } \\
\hline Median (range) & $42(1.9-4389)$ \\
\hline$\geq 35, \mathrm{n}(\%)$ & $39(57.4 \%)$ \\
\hline LN dissection, n (\%) & $69(97.2 \%)$ \\
\hline \multicolumn{2}{|l|}{ Number of LN dissected } \\
\hline Median (range) & $22(3-98)$ \\
\hline Chemotherapy & $61(85.9 \%)$ \\
\hline
\end{tabular}

FIGO, International Federation of Gynecology and Obstetrics; LN, lymph node. *CA125 was available in 68 women.

(27.3\%), 12 month in two (9.1\%), 60 months in five (22.7\%), and more than 60 months in nine (40.9\%).

Table 2 summarizes the patient-reported GCLQ data measured as "present with the past 4 weeks". Symptoms in order of frequency were numbness (40.8\%), firmness/tightness $(22.5 \%)$, swelling (22.5\%), heaviness $(22.5 \%)$, limited movement of knee (21.1\%), aching (21.1\%), leg or foot feel weakness $(18.3 \%)$, stiffness $(15.5 \%)$, increased temperature in the leg (12.7\%), limited movement of ankle (11.3\%), and limited movement of foot (11.3\%). The GCLQ score was significantly higher in patients with ever LEE compared to no LEE $(p<0.01)$.

Of the 29 patients with ever LEE, 10 (34.5\%) patients made efforts to reduce the LEE by leg elevation using a pillow $(n=8)$, remedial exercise $(n=3)$, and other personalized exercise $(n=1)$. Of the 71 patients with early ovarian cancer and LND, only $52.1 \%(37 / 71)$ of the patients replied that they had general knowledge for LLL: $86.2 \%(25 / 29)$ and $28.6 \%(12 / 42)$ in patients with ever LEE and no LEE, respectively.

\section{Discussion}

This is the first report to our knowledge that specifically addresses the incidence and duration of LEE in the ovarian cancer. The prevalence of ever LEE was 40.8, past was 18.3, and current was $22.5 \%$. Most of the LEE (86.2\%, 25/29) developed within 12 months after surgery and LEE lasted more than 6 months in approximately two-thirds of the patients $(62.1 \%, 18 / 29)$.

The onset of LEE is consistent with previous results $[6,9]$. LEE and LLL are an important problem for ovarian cancer patients, because the current standard surgical treatment of ovarian cancer include lymph node dissection [10]. However, the real clinical impact of LEE and LLL on quality of life has not been specifically investigated (Table 3 ). We routinely offer education concerning the risk of lymphedema, lymphocyst, and dermatolymphangitis, and guidelines to prevent LLL in our routine clinical practice. More recently, we instituted a policy where all patients scheduled to undergo LND watch a video of exercise for lymphedema before surgery. However, only half of the patients with early ovarian cancer responded that they are aware of LLL. It seems that knowledge for lymphedema might be acquired post-LEE, considering the appreciable difference of knowledge depending on the existence of LEE (86.2\% vs. 28.6\%). Action and study for effective health care provider-patient communication is needed to narrow the gap between health care provider efforts and patient knowledge [11].

From two randomized trials of LND, the risk of LLL significantly increased in a group with systematic LND compared to a group with lymph node sampling in early (5.8\% vs. $0 \%$ ) and advanced (6.5\% vs. $0 \%$ ) ovarian cancer $[12,13]$. The site of the lymph node dissected is an important factor related to LEE/LLL. Paraaortic LND (25.8 vs. $31.7 \%, p=0.158$ ) does not increase the risk of LLL [9]. The prevalence of LEE was significantly elevated after LND including the groin: $18.0 \%$ for pelvis and paraaortic; $20.2 \%$ for pelvis only; $50 \%$ for pelvis and groin, and $62.2 \%$ for groin only [6]. Groin and pelvis is the critical area for LEE/LLL. Paraaortic LND is not a risk factor $[5,6]$. In this study, most of women with early ovarian cancer underwent systematic LND in the pelvis and paraaortic area. Retroperitoneal closure was investigated and found not to be a risk factor of LEE despite a significant numerical difference $(41.7 \%$ vs. $22.2 \%)$ [14]. Because of the small number of patients $(n=21)$, further studies are needed to confirm this. In this study, only 

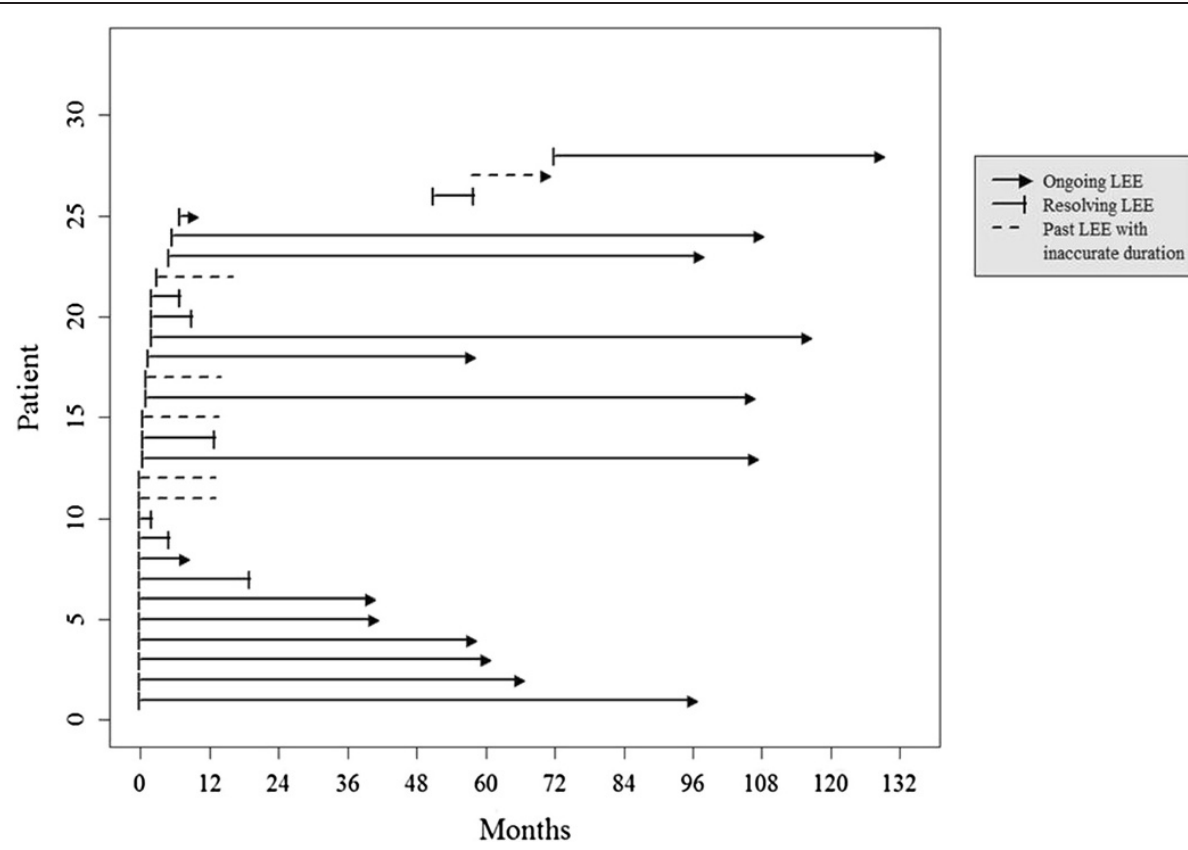

Figure 2 Onset and duration of lower extremity edema in early ovarian cancer. One line is omitted because of obscure onset and duration in one patient.

Table 2 Frequency on the Gynecologic Cancer Lymphedema Questionnaire (GCLQ) items in early ovarian cancer $(\mathbf{n}=71)$

\begin{tabular}{|c|c|c|c|c|c|c|c|}
\hline \multicolumn{8}{|l|}{ Variables } \\
\hline GCLQ items & SC & $\begin{array}{l}\text { GCLQ lower extremity lymphedema } \\
\text { symptoms items }\end{array}$ & Total n (\%) & Past LEE $\mathrm{n}(\%)$ & Current LEE n (\%) & Ever LEE n (\%) & No LEE $\mathrm{n}(\%)$ \\
\hline 15 & N & Experienced numbness & $29(40.8 \%)$ & $4(5.6 \%)$ & $8(11.3 \%)$ & $12(16.9 \%)$ & $17(23.9 \%)$ \\
\hline 12 & N & Experienced firmness/tightness & $16(22.5 \%)$ & $1(1.4 \%)$ & $8(11.3 \%)$ & $9(12.7 \%)$ & 7 (9.9\%) \\
\hline 8 & SW & Experienced swelling & $16(22.5 \%)$ & $2(2.8 \%)$ & $12(16.9 \%)$ & 14(19.7\%) & $2(2.8 \%)$ \\
\hline 14 & $\mathrm{H}$ & Experienced heaviness & $16(22.5 \%)$ & $2(2.8 \%)$ & 7 (9.9\%) & $9(12.7 \%)$ & 7 (9.9\%) \\
\hline 2 & $\mathrm{PF}$ & Limited movement of your knee & $15(21.1 \%)$ & $2(2.8 \%)$ & $4(5.6 \%)$ & $6(8.5 \%)$ & $9(12.7 \%)$ \\
\hline 17 & A & Experienced aching & $15(21.1 \%)$ & $0(0.0 \%)$ & 7 (9.9\%) & 7 (9.9\%) & $8(11.3 \%)$ \\
\hline 6 & $\mathrm{PF}$ & Leg or foot feel weak & $13(18.3 \%)$ & $2(2.8 \%)$ & $4(5.6 \%)$ & $6(8.5 \%)$ & 7 (9.9\%) \\
\hline 16 & N & Experienced stiffness & $11(15.5 \%)$ & $1(1.4 \%)$ & $3(4.2 \%)$ & $4(5.6 \%)$ & 7 (9.9\%) \\
\hline 13 & INF & Experienced increased temperature in the leg & $9(12.7 \%)$ & $0(0.0 \%)$ & $3(4.2 \%)$ & $3(4.2 \%)$ & $6(8.5 \%)$ \\
\hline 3 & $\mathrm{PF}$ & Limited movement of your ankle & $8(11.3 \%)$ & $1(1.4 \%)$ & $3(4.2 \%)$ & $4(5.6 \%)$ & $4(5.6 \%)$ \\
\hline 4 & $\mathrm{PF}$ & Limited movement of your foot & $8(11.3 \%)$ & $1(1.4 \%)$ & $4(5.6 \%)$ & $5(7.0 \%)$ & $3(4.2 \%)$ \\
\hline 19 & LSW & Experienced groin swelling & $6(8.5 \%)$ & $0(0.0 \%)$ & $4(5.6 \%)$ & $4(5.6 \%)$ & $2(2.8 \%)$ \\
\hline 1 & $\mathrm{PF}$ & Limited movement of your hip & $5(7.0 \%)$ & $1(1.4 \%)$ & $0(0.0 \%)$ & $1(1.4 \%)$ & $4(5.6 \%)$ \\
\hline 5 & $\mathrm{PF}$ & Limited movement of your toe & $5(7.0 \%)$ & $1(1.4 \%)$ & $2(2.8 \%)$ & $3(4.2 \%)$ & $2(2.8 \%)$ \\
\hline 10 & INF & Experienced redness & $4(5.6 \%)$ & $1(1.4 \%)$ & $2(2.8 \%)$ & $3(4.2 \%)$ & $1(1.4 \%)$ \\
\hline 7 & $\mathrm{~N}$ & Experienced tenderness & $3(4.2 \%)$ & $0(0.0 \%)$ & $3(18.8 \%)$ & $3(4.2 \%)$ & $0(0.0 \%)$ \\
\hline 9 & SW & Experienced swelling with pitting & $3(4.2 \%)$ & $1(1.4 \%)$ & $2(2.8 \%)$ & $3(4.2 \%)$ & $0(0.0 \%)$ \\
\hline 18 & LSW & Experienced hip swelling & $3(4.2 \%)$ & $0(0.0 \%)$ & $1(1.4 \%)$ & $1(1.4 \%)$ & $2(2.8 \%)$ \\
\hline 11 & INF & Experienced blistering & $2(2.8 \%)$ & $0(0.0 \%)$ & $0(0.0 \%)$ & $0(0.0 \%)$ & $2(2.8 \%)$ \\
\hline 20 & SW & Experienced pockets of fluid & $0(0.0 \%)$ & $0(0.0 \%)$ & $0(0.0 \%)$ & $0(0.0 \%)$ & $0(0.0 \%)$ \\
\hline
\end{tabular}

$\mathrm{A}$, ache; $\mathrm{H}$, heaviness; INF, infection; LEE, lower extremity edema; LLL, lower leg lymphedema; LSW, limb swelling; $N$, neuropathy; $n$, number; PF, physical function; $\mathrm{SC}$, symptoms cluster; SW, swelling general. 


\begin{tabular}{|c|c|c|c|c|c|c|c|c|}
\hline First author & Year & Study design & $\begin{array}{l}\text { N. of OC } \\
\text { patients } \\
\text { (N. of total } \\
\text { GC patients) }\end{array}$ & Stage & Diagnostic criteria & Incidence (\%) & $\begin{array}{l}\text { Risk factor } \\
\text { for LEE/LLL }\end{array}$ & Comment \\
\hline \multirow[t]{4}{*}{ Ryan M. } & \multirow[t]{4}{*}{2003} & \multirow[t]{4}{*}{ CQ \& MRR } & \multirow[t]{4}{*}{$141(487)$} & \multirow[t]{4}{*}{ NA } & \multirow[t]{4}{*}{. Diagnosed LLL } & $7.1 \%(10 / 141)$ in OC & \multirow[t]{4}{*}{-} & \multirow{4}{*}{$\begin{array}{l}\text { MTFOTL: } 3,6,12 \text {, and } 60 \text { months in } 53 \text {, } \\
18,13, \text { and } 16 \% \text { of the patients with GC. } \\
\text { Highest rate of LLL after GLND (50-62.2\%). }\end{array}$} \\
\hline & & & & & & - $18.3 \%(89 / 487)$ in all GC & & \\
\hline & & & & & & $62.2 \%(28 / 45)$ after GLND & & \\
\hline & & & & & & $\begin{array}{l}50.0 \%(47 / 233) \text { after } \\
\text { GLND + PLND }\end{array}$ & & \\
\hline \multirow[t]{2}{*}{ Panici PB. } & \multirow[t]{2}{*}{2005} & \multirow{2}{*}{$\begin{array}{l}\text { Multi-center } \\
\text { Italian RCT }\end{array}$} & \multirow[t]{2}{*}{427} & III, 406 (95.1\%) & \multirow[t]{2}{*}{ · Diagnosed LLL } & \multirow{2}{*}{$\begin{array}{l}6.5 \%(14 / 216) \text { vs. } 0 \% \\
(0 / 211) \text { in SL vs. LNS }\end{array}$} & \multirow[t]{2}{*}{ SL compared to LNS } & \multirow[t]{2}{*}{ - Improvement of SL on PFS, but not OS. } \\
\hline & & & & IV, 21 (4.9\%) & & & & \\
\hline \multirow[t]{2}{*}{ Magginoi A. } & \multirow[t]{2}{*}{2006} & \multirow{2}{*}{$\begin{array}{l}\text { Multi-center } \\
\text { Italian RCT }\end{array}$} & \multirow[t]{2}{*}{268} & I, $192(72.7 \%)$ & \multirow[t]{2}{*}{. Diagnosed LLL } & \multirow{2}{*}{$\begin{array}{l}5.8 \%(8 / 138) \text { vs. } 0 \% \\
(0 / 130) \text { in SL vs. LNS }\end{array}$} & \multirow[t]{2}{*}{ SL compared to LNS } & \multirow[t]{2}{*}{ No improvement of SL on PFS and OS. } \\
\hline & & & & II, $72(27.3 \%)$ & & & & \\
\hline \multirow[t]{2}{*}{ Beesley V. } & \multirow[t]{2}{*}{2007} & \multirow[t]{2}{*}{ PRO via mail } & \multirow[t]{2}{*}{$234(802)$} & \multirow[t]{2}{*}{ NA } & $\cdot P R O-L E E$ & $\cdot$ LEE, $15.8 \%(37 / 234)$ & \multirow[t]{2}{*}{-} & - Lowest incidence (4.7\%) of LLL among GC \\
\hline & & & & & Diagnosed LLL & LLL, $4.7 \%(11 / 234)$ & & BMI is not risk factor. \\
\hline \multirow[t]{2}{*}{ Tanaka T. } & \multirow[t]{2}{*}{2007} & \multirow[t]{2}{*}{ CQ \& MRR } & \multirow[t]{2}{*}{$21(184)$} & I-II, 17 (81\%) & $\cdot P R O-L E E$ & $41.7 \%(5 / 12)$ in RC vs. & - & $\mathrm{RC}$ is not risk factor. This should be \\
\hline & & & & III-IV, 4 (19\%) & & $\cdot 22.2 \%(2 / 9)$ in non-RC & & $\begin{array}{l}\text { investigated again in larger number } \\
\text { of patients. }\end{array}$ \\
\hline Tada H. & 2009 & Multi-center & $135(694)$ & I-II, 75 (55.6\%) & Diagnosed \& & $20.7 \%(28 / 135)$ & RT, OR 1.79 & MTFOTL: $4.6(0.1-40.2)$ months \\
\hline & & $\begin{array}{l}\text { Japanese } \\
\text { Retrospective }\end{array}$ & & III-IV, 60 (44.4\%) & & & $(95 \% C \mathrm{Cl}, 1.20-2.68)$ & . LLL, 25.8 vs. $31.7 \%$ in PALND(-) vs. (+) \\
\hline Matsuo K. & 2011 & Retrospective & 276 & I-II, 43 (15.6\%) & - MRR & LEE, 6.5\% (18/276) & - & - LEE at initial diagnosis is an important \\
\hline & & & & III-IV, 233 (84.5\%) & & & & $\begin{array}{l}\text { On PFS ( } 4.9 \text { vs. } 15.3 \text { months) and } \\
\text { OS (5.9 and } 49.1 \text { months). }\end{array}$ \\
\hline & & & & & & & & . LEE is the 14 th symptoms. \\
\hline Karlan BY. & 2012 & $\mathrm{RCT}$ & 161 & Recurrent OC & . Peripheral edema & $\begin{array}{l}\text { LEE, } 51-71 \% \text { vs. } 22 \% \text { in } \\
\text { AMG } 386^{*} \text { vs. Control }\end{array}$ & $\begin{array}{l}\text { AMG386 administered } \\
\text { patients }\end{array}$ & $\begin{array}{l}\text { LEE, } 51 \text { \& } 71 \% \text { (AMG } 3863 \text { \& } 10 \mathrm{mg} / \mathrm{kg} \\
\text { OW with paclitaxel QW) vs. } 22 \% \text { in AMG } \\
386^{*} \text { vs. Control (weekly paclitaxel } \\
(80 \mathrm{mg} / \mathrm{m} 2 \mathrm{QW})\end{array}$ \\
\hline Achouri A. & 2012 & Retrospective & $36(88)$ & NA & Diagnosed LLL & $5.6 \%(2 / 36)$ & $\begin{array}{l}\text { Postoperative drainage, } \\
\text { OR } 0.13(95 \% \mathrm{Cl}, 0.02-0.69)\end{array}$ & $\begin{array}{l}\text { - Incidence of LLL, } 11.4 \% \text { and } 23.5 \% \text { in } \\
\text { EC and CC. }\end{array}$ \\
\hline & & & & & & & & $\begin{array}{l}\text { BMI, surgical approach (laparoscopy } \\
\text { and laparotomy), PALND, SPOL, number } \\
\text { of LND is not risk factor for LLL }\end{array}$ \\
\hline
\end{tabular}


Table 3 Incidence and risk factors of edema and/or lymphedema of lower leg after treatment of ovarian cancer (Continued)

\begin{tabular}{|c|c|c|c|c|c|c|c|c|}
\hline \multirow[t]{2}{*}{ Lim MC. } & \multirow{2}{*}{$\begin{array}{l}2013 \\
\text { Current } \\
\text { study }\end{array}$} & \multirow[t]{2}{*}{$C Q \& M R R$} & \multirow[t]{2}{*}{71} & I, $52(73.3 \%)$ & \multirow[t]{2}{*}{ - PRO - LEE } & \multirow[t]{2}{*}{$40.8 \%(29 / 71)$} & - & $\begin{array}{l}\text { - MTFOTL: }<1,3,6 \text {, and } 12 \text { months } \\
\text { in } 63,18.5,7.4 \text {, and } 3.7 \%\end{array}$ \\
\hline & & & & & & & & $\begin{array}{l}\text { Median duration of LEE: }<6,12,60 \text {, } \\
\text { and } \geq 60 \text { in } 27.3,9.1,22.7 \text {, and } 40.9 \%\end{array}$ \\
\hline
\end{tabular}

BMI, body mass index; CC, cervical cancer; CQ, cross-sectional questionnaire; EC, endometrial cancer; GC, gynecologic cancer; GLND, groin lymph node dissection; LEE, lower extremity edema; LLL, lower leg

lymphedema; LND, lymph node dissection; LNS, lymph node sampling; MRR, medical record review; MTFOTL, median time from operation to lower extremity edema; N, number; NA, not available; OC, ovarian cancer;

OS, overall survival; PALN, paraaortic lymph node; PALND, paraaortic lymph node dissection; PFS, progression free survival; PLN, pelvic lymph node; PLND, pelvic lymph node dissection; PRO, patient reported outcomes;

$\mathrm{QW}$, once weekly; RC, retroperitoneal closure; RCT, randomized trial; RT, radiotherapy; SL, systemic pelvic and aortic lymph node dissection; SPOL, symptomatic postoperative lymphocele.

*AMG386, an investigational peptide-Fc fusion protein that neutralizes the interaction between the Tie2 receptor and angiopoietin-1/2. 
the peritoneum of the aortic area was closed in patients with ovarian cancer. The exact role of retroperitoneal closure should be confirmed in a large patient cohort. Body mass index, surgical approach (laparotomy vs. laparoscopy), and symptomatic postoperative lymphocele are not risk factors of LEE/LLL $[4,5]$.

Two randomized trials analyzed survival for systematic LND in ovarian cancer [12,13]. In one study, systemic LND improved only progress-free survival in advanced ovarian cancer [13]. In early ovarian cancer, there is no survival benefit from systematic LND [12]. The power was $80 \%$ implying insufficient power to exclude clinically important effects of systematic LND on survival [12]. LND is still one of the standard staging and cytoreductive surgical procedures. At this point, gynecologic oncologists, medical oncologists who perform adjuvant chemotherapy, and patients with ovarian cancer should be aware of the pattern of LEE/LEE [10]. Figure 2 illustrates the pattern of LEE after cytoreductive surgery and adjuvant chemotherapy, in close agreement with previous studies [6,9]. We first investigated the duration of LEE (Figure 2). This information should be discussed with patients before LND.

On the other hand, Matsuo et al. reported that LEE at time of the initial diagnosis of ovarian cancer is a strong prognostic indicator of PFS (4.9 vs. 15.3 months, $p<0.01$ ) and overall survival (5.9 and 49.1 months, $p<0.01$ ) [15]. Previously, we reported that LEE as a clinical manifestation of deep vein thrombosis, suggesting disease burden, might be a poor prognostic marker in survival of ovarian cancer [16,17]. In the current study, $41.4 \%(12 / 29)$ of the patients responded that they had LEE immediately after surgery. However, the prognostic role of LEE is difficult to analyze because of the limited disease failure in early ovarian cancer. Theoretically, LEE could easily develop in patients with deep vein thrombosis from extensive disease and compression of lymphatic vessel from bulky lymph node metastasis. The prognostic role of LEE in ovarian cancer should be investigated.

The limitations of this study are that it was not a prospective study, that LEE/LLL related events like postoperative lymphocyst and/or dermatolymphangitis were not analyzed, and the lack of confirmation of the relationship of LEE and LLL because a significant portion of the patients in this study visited only annually. And there is a possibility of bias because this was a retrospective and cross-sectional study. The strengths of this study are the homogenous patient cohort in terms of stage, surgical principle, and adjuvant chemotherapy; the use of a validated questionnaire [7]; and the clear description of the duration of LEE.

\section{Conclusions}

In the current study, significant numbers of patients with ovarian cancer have LEE after primary treatment of ovarian cancer. However, most of them were unfamiliar with lymphedema until they actually develop LEE. Therefore, preoperative and postoperative counseling and education for prevention and early sign of LEE/LLL should be provided to the patients who will undergo LND. And prospective studies for effective educational interventions on LEE/LLL are needed in patients with ovarian cancer.

\section{Abbreviations}

FIGO: International Federation of Gynecology and Obstetrics; LEE: Lower extremity edema; LLL: Lower leg lymphedema; LND: Lymph node dissection.

\section{Competing interests}

No potential competing interest are disclosed.

\section{Authors' contributions}

MCL and SYP managed the overall project. All authors participated in research design and contributed to the writing and revising of the manuscript. JSL surveyed and collected all data. BHN performed primary analysis of the data. All authors read and approved the final manuscript.

\section{Acknowledgements}

This work was supported by grants from the Korean National Cancer Center (1210510).

\section{Author details}

${ }^{1}$ Center for Uterine Cancer, Research Institute and Hospital, National Cancer Center, 323, Ilsan-ro, Ilsandong-gu, Goyang-si 410-769, Gyeonggi-do, Republic of Korea. ${ }^{2}$ Gynecologic Cancer Branch, Research Institute and Hospital, National Cancer Center, 323, Ilsan-ro, Ilsandong-gu, Goyang-si 410-769, Gyeonggi-do, Republic of Korea. ${ }^{3}$ Biostatistics Biometric Research Branch, Research Institute and Hospital, National Cancer Center, 323, Ilsan-ro, Ilsandong-gu, Goyang-si 410-769, Gyeonggi-do, Republic of Korea.

Received: 21 January 2014 Accepted: 3 March 2014

Published: 7 March 2014

\section{References}

1. Lim MC, Moon EK, Shin A, Jung KW, Won YJ, Seo SS, Kang S, Kim JW, Kim JY, Park SY: Incidence of cervical, endometrial, and ovarian cancer in Korea, 1999-2010. J Gynecol Oncol 2013, 24(4):298-302.

2. Jung KW, Won YJ, Kong HJ, Oh CM, Seo HG, Lee JS: Cancer statistics in Korea: incidence, mortality, survival and prevalence in 2010. Cancer Res Treat: J Korean Cancer Assoc 2013, 45(1):1-14.

3. Chiang YC, Chen CA, Chiang CJ, Hsu TH, Lin MC, You SL, Cheng WF, Lai MS: Trends in incidence and survival outcome of epithelial ovarian cancer: 30-year national population-based registry in Taiwan. J Gynecol Oncol 2013, 24(4):342-351.

4. Beesley V, Janda M, Eakin E, Obermair A, Battistutta D: Lymphedema after gynecological cancer treatment: prevalence, correlates, and supportive care needs. Cancer 2007, 109(12):2607-2614.

5. Achouri A, Huchon C, Bats AS, Bensaid C, Nos C, Lecuru F: Postoperative lymphocysts after lymphadenectomy for gynaecological malignancies: preventive techniques and prospects. Eur J Obstet Gynecol Reprod Biol 2012, 161(2):125-129.

6. Ryan M, Stainton MC, Slaytor EK, Jaconelli C, Watts S, Mackenzie P. Aetiology and prevalence of lower limb lymphoedema following treatment for gynaecological cancer. Aust N Z J Obstet Gynaecol 2003, 43(2):148-151.

7. Carter J, Raviv L, Appollo K, Baser RE, lasonos A, Barakat RR: A pilot study using the Gynecologic Cancer Lymphedema Questionnaire (GCLQ) as a clinical care tool to identify lower extremity lymphedema in gynecologic cancer survivors. Gynecol Oncol 2010, 117(2):317-323.

8. Lim MC, Lee JS, Joo J, Park K, Yoo HJ, Seo SS, Kang S, Chung SH, Park SY: Development and evaluation of the korean version of the gynecologic cancer lymphedema questionnaire in gynecologic cancer survivors. Gynecol Oncol 2014. Article in press, http://dx.doi.org/10.1016/j. ygyno.2014.01.040. 
9. Tada H, Teramukai S, Fukushima M, Sasaki H: Risk factors for lower limb lymphedema after lymph node dissection in patients with ovarian and uterine carcinoma. BMC Cancer 2009, 9:47.

10. Schorge JO, Eisenhauer EE, Chi DS: Current surgical management of ovarian cancer. Hematol Oncol Clin North Am 2012, 26(1):93-109.

11. Stewart MA: Effective physician-patient communication and health outcomes: a review. CMAJ 1995, 152(9):1423-1433.

12. Maggioni A, Benedetti Panici P, Dell'Anna T, Landoni F, Lissoni A, Pellegrino A, Rossi RS, Chiari S, Campagnutta E, Greggi S, Angioli R, Manci N, Calcaqno M, Scambia G, Fossati R, Floriani I, Torri V, Grassi R, Manqioni C: Randomised study of systematic lymphadenectomy in patients with epithelial ovarian cancer macroscopically confined to the pelvis. Br J Cancer 2006, 95(6):699-704.

13. Panici PB, Maggioni A, Hacker N, Landoni F, Ackermann S, Campagnutta E, Tamussino K, Winter R, Pellegrino A, Greggi S, Angioli R, Manci N, Scambia G, Dell'Anna T, Fossati R, Floriani I, Rossi RS, Grassi R, Favalli G, Raspagliesi F, Giannarelli D, Martella L, Manqioni C: Systematic aortic and pelvic lymphadenectomy versus resection of bulky nodes only in optimally debulked advanced ovarian cancer: a randomized clinical trial. J Natl Cancer Inst 2005, 97(8):560-566.

14. Tanaka T, Ohki N, Kojima A, Maeno Y, Miyahara Y, Sudo T, Takekida S, Yamaguchi S, Sasaki H, Nishimura R: Radiotherapy negates the effect of retroperitoneal nonclosure for prevention of lymphedema of the legs following pelvic lymphadenectomy for gynecological malignancies: an analysis from a questionnaire survey. Int I Gynecol Cancer 2007, 17(2):460-464.

15. Matsuo K, Ahn EH, Prather CP, Eno ML, Im DD, Rosenshein NB: Patient-reported symptoms and survival in ovarian cancer. Int I Gynecol Cancer 2011, 21(9):1555-1565.

16. Lim MC, Park SH, Park SY: Ovarian clear cell carcinoma: high risk of venous thromboembolism. Gynecol Oncol 2010, 118(3):317. author reply 317-318.

17. Lim MC, Lee HS, Kang S, Seo SS, Lee BY, Park SY: Minimizing tumor burden by extensive cytoreductive surgery decreases postoperative venous thromboembolism in ovarian clear cell carcinoma. Arch Gynecol Obstet 2010, 281(2):329-334.

doi:10.1186/1757-2215-7-28

Cite this article as: Lim et al:: Lower extremity edema in patients with early ovarian cancer. Journal of Ovarian Research 2014 7:28.

\section{Submit your next manuscript to BioMed Central and take full advantage of:}

- Convenient online submission

- Thorough peer review

- No space constraints or color figure charges

- Immediate publication on acceptance

- Inclusion in PubMed, CAS, Scopus and Google Scholar

- Research which is freely available for redistribution 